\section{A novel technique for closure of post excisional soft tissue defects of axillary hidradenitis suppurativa}

Sir,

We write this letter to present a novel technique for closure of soft tissue defects of Axillary Hidradenitis Suppurativa excision by 'Sure Closure - Skin Stretching System'. To the best of our knowledge, this technique has never been reported anywhere in the literature for post excisional soft tissue defects of Axillary Hidradenitis Suppurativa.

Hidradenitis Suppurativa is a recurrent disease of the apocrine gland-bearing areas causing painful, deepseated lesions, and draining sinus tracts predominantly in axilla, groin, perineum and buttocks which usually develops after puberty with a female preponderance and is associated with increased pain and suppuration at varying intervals..$^{[1]}$

Delay in diagnosis is common as it is often mistaken for a simple infection and excision is the treatment of choice. ${ }^{[2]}$

A 25-year-old obese lady presented with multiple recurrent draining sinus tracts in left axillary region

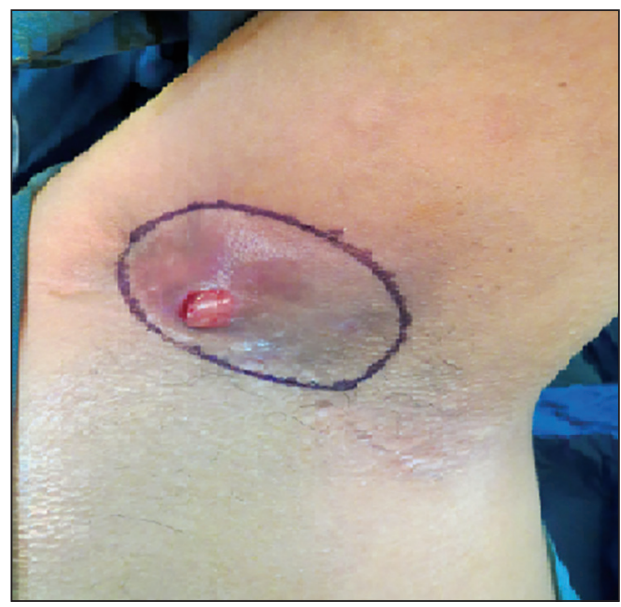

Figure 1: Multiple recurrent draining sinus tracts in left axillary region
[Figure 1], which were not responding to antibiotics for which she underwent excision of the primary lesion. Resultant defect after excision was circular in shape of $7 \mathrm{~cm}$ diameter [Figure 2]. The defect was closed with Sure Closure - Skin Stretching System [Figures 3-6].

Providing cover for soft tissue defects, which cannot be closed primarily or skin grafted, has always posed a challenge for surgeons. Commonly adopted reconstructive options are local and pedicled flaps as well as microvascular free tissue transfer.

Many surgeons also utilize the stretchability of the skin by placing tissue expanders preoperatively but they again are expensive and need an additional procedure in addition to the period of discomfort and disfigurement during the period of expansion and also the possible attendant risk of compromised viability.

Sure Closure - Skin Stretching System exerts a controlled amount of tension along the wound margins. The load is kept constant over time and the skin in accordance to its viscoelastic properties is stretched and extended. ${ }^{[3]}$ Moreover, its tendency for recoil is also minimized. The process is known as 'mechanical creep' and does not impair immediate or long-term viability of the skin. ${ }^{[4]}$

The notable advantages of this system are that it avoids undermining of the skin edges, can be done as a bedside procedure under local anaesthesia and reduces the cost of treatment and hospital stay.

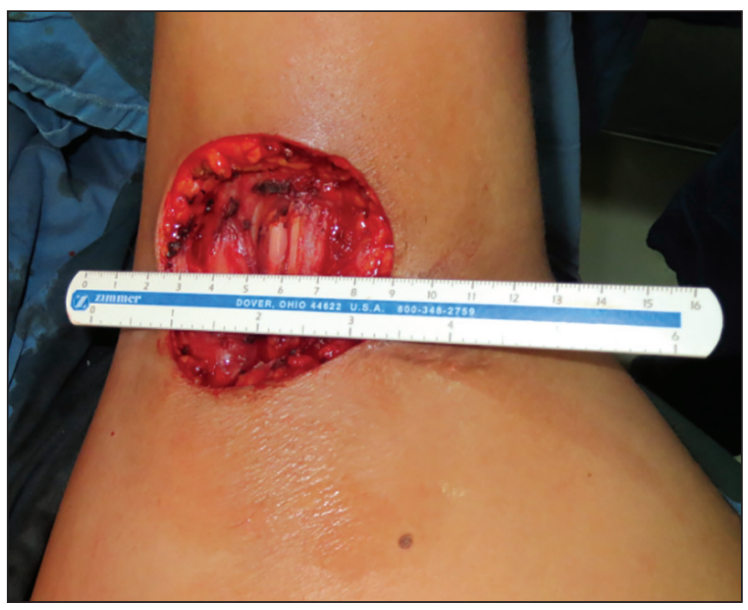

Figure 2: Post excisional defect 


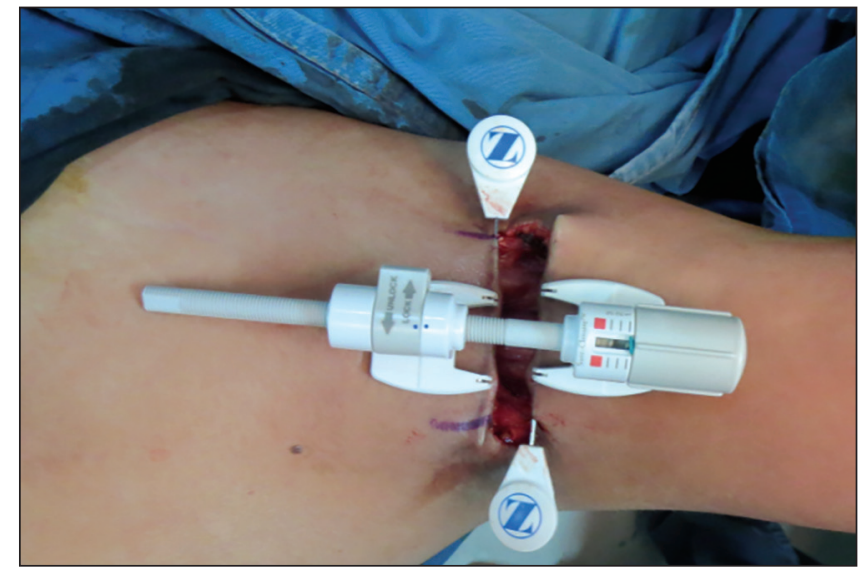

Figure 3: Closure using sure closure device

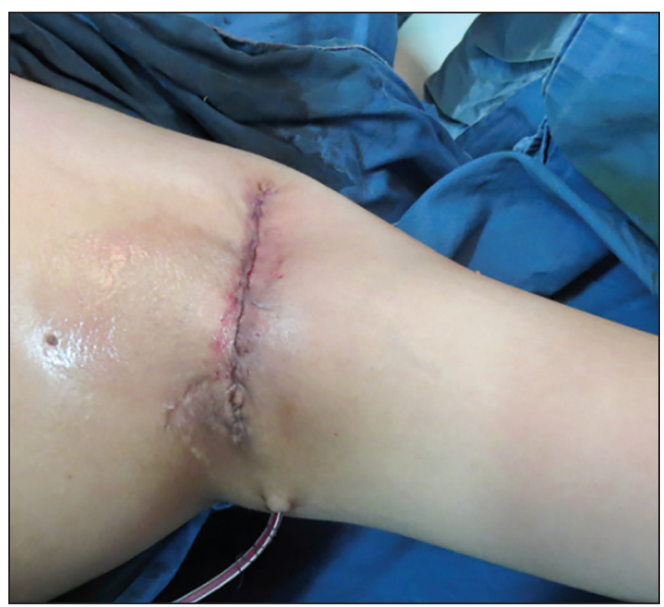

Figure 5: Immediate post-operative phase post-operative day 0

However, it does have a higher propensity for hypertrophic scar formation, infection of intradermal pin tracts and Ischemic necrosis of the skin edges if adequate care is not given while stretching.

In conclusion, the proper use of Sure Closure - Skin Stretching System can save the need for a major surgical procedure in many patients with axillary defects.

\section{Mohit Sharma, Saurabh Sharma, Raghuveer Reddy Dudipala}

Department of Plastic and Reconstructive Surgery, Amrita Institute of Medical Sciences, Kochi, Kerala, India

Address for correspondence:

Dr. Raghuveer Reddy Dudipala, Department of Plastic and Reconstructive Surgery, Amrita Institute of Medical Sciences, AIMS Ponekkara P.O Kochi - 682 041, Kerala, India. E-mail: reddysunny@hotmail.com

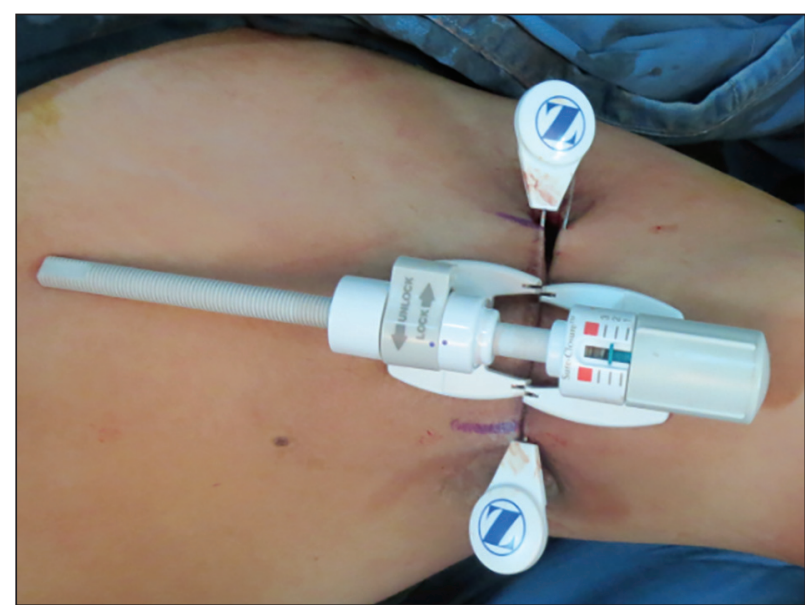

Figure 4: Closure using sure closure device - serial approximation of the wound margins

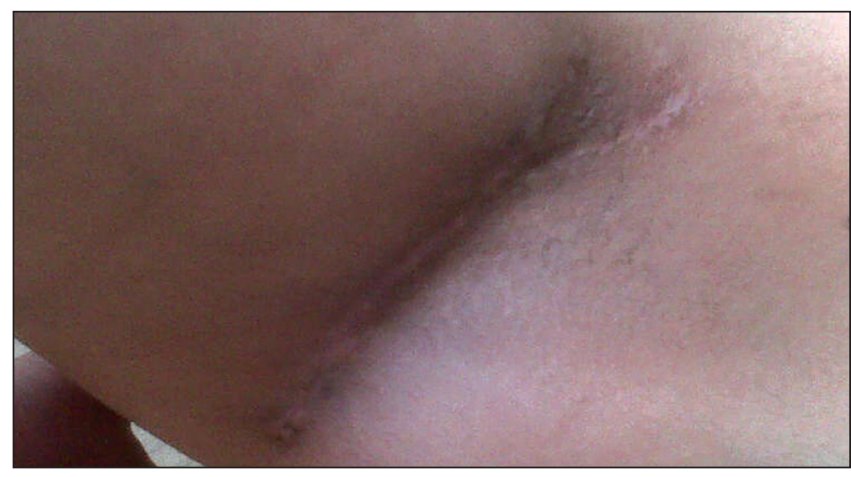

Figure 6: Well healed wound margins on follow-up at 3 months

\section{REFERENCES}

1. Jemec GB. Clinical practice. Hidradenitis suppurativa. N Engl J Med 2012;366:158-64.

2. Tasche C, Angelats J, Jayaram B. Surgical treatment of hidradenitis suppurativa of the axilla. Plast Reconstr Surg 1975;55:559-62.

3. Hirshowitz B, Jackson IT. An attempt to harness the viscoelastic properties of skin in face lift operations - a preliminary report. Ann Plast Surg 1987;18:188-99.

4. Hirshowitz B, Baum EL, Har-Shai Y. A skin-stretching device for harnessing of the visco-elastic properties of skin. J Plast Reconst Surg 1994;92:260.

\begin{tabular}{|l|l|}
\hline \multicolumn{2}{|c|}{ Access this article online } \\
\hline Quick Response Code: & Website: \\
\hline & www.ijps.org \\
\cline { 2 - 2 } & DoI: \\
\hline
\end{tabular}

